\title{
Implementation of an Affordable Method for MPS Diagnosis from Urine Screening to Enzymatic Confirmation: Results of a Pilot Study in Morocco
}

\author{
Naima Fdil ${ }^{1}$, Es-Said Sabir ${ }^{1}$, Aicha Ezoubeiri ${ }^{2}$, Rabiy Elqadiry ${ }^{3}$, Abderahmane Daoudi ${ }^{3}$, \\ Abdessamad Lalaoui ${ }^{3}$, Adil Fouad ${ }^{3}$, Noureddine Rada ${ }^{3}$, Nadia Slitine ${ }^{4}$, Fatiha Bennaoui ${ }^{4}$, \\ Aicha Bourrahouat ${ }^{3}$, Imane Ait Saab ${ }^{3}$, Brahim Boualy ${ }^{5}$, Abdallah Karim ${ }^{6}$, Fernando Andrade ${ }^{7}$, \\ Domingo gonzález-Lamuňo ${ }^{8}$, Luis aldámiz-Echevarria ${ }^{7}$, Mohammed Bouskraoui ${ }^{3}$ \\ ${ }^{1}$ Metabolic Platform, Biochemistry Laboratory, School of Medicine, Cadi Ayad University, Marrakech, Morocco \\ ${ }^{2}$ Clinical Analysis Laboratory, Ibn Tofail Hospital, Mohammed VI University Hospital, Marrakesh, Morocco \\ ${ }^{3}$ Mother-Child Hospital, Pediatric Department, Mohammed VI University Hospital, Cadi Ayad University, Marrakesh, Morocco \\ ${ }^{4}$ Neonatal Care Department, Mohammed VI University Hospital, Marrakesh, Morocco \\ ${ }^{5}$ Khouribga Multidisciplinary Faculty, Chemistry Department, Sultan Moulay Sliman University, Khouribga, Morocco \\ ${ }^{6}$ Laboratory of Coordination Chemistry, Faculty of Sciences Semlalia, Cadi Ayad University, Morocco \\ ${ }^{7}$ Division of Metabolism, Department of Paediatrics, Cruces Hospital, Barakaldo, Vizcaya, Spain \\ ${ }^{8}$ Diagnosis and Advanced Metabolic Studies Center of Cantabria, Marqués de Valdecilla University Hospital, Santander, Spain
}

\begin{abstract}
SUMMARY
Background: Rapid and accurate diagnosis of mucopolysaccharidoses (MPS) is still a challenge due to poor access to screening and diagnostic methods and to their extensive clinical heterogeneity. The aim of this work is to perform laboratory biochemical testing for confirming the diagnosis of mucopolysaccharidosis (MPS) for the first time in Morocco.

Methods: Over a period of twelve months, 88 patients suspected of having Mucopolysaccharidosis (MPS) were referred to our laboratory. Quantitative and qualitative urine glycosaminoglycan (GAG) analyses were performed, and enzyme activity was assayed on dried blood spots (DBS) using fluorogenic substrates. Enzyme activity was measured as normal, low, or undetectable.

Results: Of the 88 patients studied, 26 were confirmed to have MPS; 19 MPS I (Hurler syndrome; OMIM \#607014/Hurler-Scheie syndrome; OMIM \#607015), 2 MPS II (Hunter syndrome; OMIM \#309900), 2 MPS IIIA (Sanfilippo syndrome; OMIM \#252900), 1 MPS IIIB (Sanfilippo syndrome; OMIM \#252920) and 2 MPS VI (Maroteaux-Lamy syndrome; OMIM \#253200). Parental consanguinity was present in $80.76 \%$ of cases. Qualitative urinary glycosaminoglycan (uGAGs) assays showed abnormal profiles in 31 cases, and further quantitative urinary GAG evaluation and Thin Layer Chromatography (TLC) provided important additional information about the likely MPS diagnosis. The final diagnosis was confirmed by specific enzyme activity analysis in the DBS samples.

Conclusions: The present study shows that the adoption of combined urinary substrate analysis and enzyme assays using dried blood spots can facilitate such diagnosis, offer an important tool for an appropriate supporting care, and a specific therapy, when available.
\end{abstract}

(Clin. Lab. 2020;66:xx-xx. DOI: 10.7754/Clin.Lab.2019.190720)

Correspondence:

Naima Fdil

Metabolic Platform, Biochemistry Laboratory

Biochemistry Research Team

School of Medicine

Cadi Ayad University, Marrakech
Morocco

Phone: +212524339885

Fax: $\quad+212524339890$

Email: nfdil@yahoo.fr

Manuscript accepted August 28, 2019 


\section{KEY WORDS}

mucopolysaccharidosis, glycosaminoglycans, thin layer chromatography, dried blood spot

\section{LIST OF ABBREVIATIONS}

4-MU - 4-methylumbelliferone $\mathrm{CPC}$ - cetylpyridinium chloride CS - chondroitine sulfatase DBS - dried blood spot DMB - dimethyl methylene blue

DS - dermatane sulfate

ENT - ear, nose and throat

ERT - enzyme replacement therapy

GAG - glycosaminoglycan

HS - heparane sulfate

HSCT - hematopoietic stem cell transplantation

KS - keratan sulfate

LSD - lysosomal storage disease

MPS - mucopolysaccharidosis

NBS - newborn screening

TLC - thin layer chromatography

UGAGs - urinary glycosaminoglycans

\section{INTRODUCTION}

High consanguinity, difficult access to accurate diagnostic tests, and costly therapies are all significant contributors to the lysosomal disease burden. The adoption of combined urinary procedure and enzyme essays using dried blood spot can facilitate earlier diagnosis and consequent earlier consideration of therapeutic options and earlier counseling to affected families. The Mucopolysaccharidosis (MPS) is a group of metabolic disorders characterized by a deficiency in one of the lysosomal enzymes necessary for the catabolism of glycosaminoglycans (GAGs), formerly known as mucopolysaccharides [1]. Deficiency of these enzymes leads to a widespread accumulation of undegraded or partially degraded GAGs in different tissues and to excessive excretion of these substances in urine [2].

The MPS subtypes have multi-systemic clinical manifestations of variable severity. In Morocco, obtaining an early clinical MPS diagnosis has historically been a challenge and patients have not been diagnosed until more advanced stages of the disease. Early diagnosis is of paramount importance for an optimum management of inborn errors and a better prognosis. There is no national protocol for newborn screening of inborn errors of metabolism in Morocco. Affordable, easy and accurate testing of suspected patients is therefore fundamental to diagnosis and management.

\section{MATERIALS AND METHODS}

This study included 88 Moroccan patients suspected of MPS who were referred to the Biochemical Laboratory in the Marrakech Faculty of Medicine by the pediatric departments of Mohamed VI University Hospital. The patient ages ranged from 9 months to 15.6 years (median, 8 years). Most of the patients referred were from consanguineous families (74\%).

The first step in our laboratory diagnosis of these patients suspected of having an MPS was the quantitative and qualitative analysis of urinary glycosaminoglycans (uGAGs) [3,4]. An early morning urine sample (10 $20 \mathrm{~mL}$ ) was collected from each patient for the determination of GAGs using semi-quantitative, quantitative, and qualitative assays. Deficient enzyme activity testing was done using $60-70 \mu \mathrm{L}$ of whole blood spotted on filter paper (Whatman-GE no. 903) and dried for 4 hours at room temperature. Filter papers were stored at $4^{\circ} \mathrm{C}$ in plastic containers. This algorithm for patient sample analysis is shown in Figure 1.

This study was conducted in compliance with the recommendations of the Declaration of Helsinki and Good Clinical Practice (GCP) Guidelines. The study was approved by the Independent Ethics Committee of Marrakech Hospital University, and consent was obtained from patients and/or their parents or guardians.

Laboratory analysis of urinary glycosaminoglycans The GAG assay was the usual first step in making our biochemical diagnosis [5,6]. uGAGs remain stable at room temperature for up to 10 days, so urine samples do not need to be frozen for transport to the laboratory [7]. Both semi-quantitative (the GAG test) and quantitative, using dimethyl methylene blue (DMB), assays were used.

\section{Dimethyl methylene blue solution}

DMB solution was prepared according to the method described by Andrade et al. [7]. In a volumetric flask of $1 \mathrm{~L}, 10.66 \mathrm{mg}$ of DMB (research grade, purchased from Sigma-Aldrich, CAS: 931418-92-7) was added, with $3.33 \mathrm{~mL}$ of ethanol (purchased from Merck, CAS: 6417-5), $1.33 \mathrm{~g}$ of sodium formate (purchased from Merck, CAS: 141-53-7), and $1.33 \mathrm{~mL}$ of formic acid (purchased from Sigma-Aldrich, CAS: 64-18-6). The $\mathrm{pH}$ value was adjusted to 3.75 by adding more concentrated acid or solid formate. The flask was filled up to $1 \mathrm{~L}$ with distilled water. This solution has proven to be stable for at least 10 months at $5^{\circ} \mathrm{C}$. A chondroitin 6sulfate solution was prepared at $100 \mathrm{mg} / \mathrm{L}$ in distilled water. The solution is stable for at least one year at $4{ }^{\circ} \mathrm{C}$, when stored in the dark.

Semi quantitative and quantitative urinary glycosaminoglycans determination

The GAG test was performed using a colorimetric method based on the color change produced by the complexes formed between DMB and GAGs $[8,9]$. The 
DMB solution was transferred to transparent vials ( $2 \mathrm{~mL}$ ), to which $50 \mu \mathrm{L}$ of a centrifuged first morning urine was added. A high urine concentration of GAGs, which occurred in patients with MPS I, II and VI, was considered as a positive result (blue color changed to purple). A negative result was confirmed if the urinary GAG concentration was low (no color change). Finally, if the color of the GAG-tests changed to violet, it was considered as an inconclusive result.

The quantitative determination of urinary GAGs was performed on all patient samples, even if a negative reaction was observed in the first GAG test. It was performed using ultraviolet-visible spectrophotometry. For the calibration curve, we constructed a series of dilutions from a solution of chondroitin 6-sulphate: $(100 \mathrm{mg}$ $/ \mathrm{mL}$ of water) by diluting $5,10,25,50$, and $100 \mu \mathrm{L}$ in water to obtain a final volume of $500 \mu \mathrm{L}$. With the patient samples, $100 \mu \mathrm{L}$ of urine were diluted in water to obtain a final volume of $500 \mu \mathrm{L}$. After the dilution, we added $2.5 \mathrm{~mL}$ of DMB. The readings were taken using the differences between the absorbance at 520 and 600 $\mathrm{nm}[7,9]$. Spectrophotometric measurements were recorded on a UV-visible 1601 Shimadzu spectrophotometer (Shimadzu Co., Kyoto, Japan). If a particular urine sample was too diluted or concentrated, the volume of urine was increased or reduced, taking into account the appropriate dilution factor. Finally, the GAG concentration was calculated on the basis of creatinine values, determined by an automated chemistry analyzer using the Jaffe method. The final GAG results were expressed in $\mathrm{mg} / \mathrm{mmol}$ creatinine. To avoid erroneous results in the concentration of GAGs, all urine samples with a creatinine concentration of less than $20 \mathrm{mg} / \mathrm{dL}$ or more than $200 \mathrm{mg} / \mathrm{dL}$ were recollected.

Since the method of measuring total GAGs in urine is incapable of distinguishing between the different types of GAGs excreted and considering that several studies have reported that patients with MPS III, IV, and VII may have comparatively lower levels of GAGs, resulting in a false-negative result [4,10,11], a qualitative analysis of urinary GAGs was needed for the group and differential diagnosis of MPS patients, but all were further confirmed by enzyme assays.

\section{Urinary GAG Isolation}

GAGs were isolated from urine by precipitation with cetylpyridinium chloride solution (CPC), (purchased from Sigma-Aldrich, CAS: 6004-24-6) using a modified Humbel method [12]. A thin layer chromatography (TLC) assay was used to identify the specific pattern of GAG excretion. The starting volume of urine was determined on the basis of GAG concentrations of creatinine; hence urine volumes used were between 1 and $6 \mathrm{~mL}$. Urine was centrifuged at 2,000 rpm for 10 minutes at room temperature. The supernatant was added to the same volume of CPC solution, $\mathrm{pH} 4.8$; the mixture was incubated for 30 minutes at $37^{\circ} \mathrm{C}$ in a water bath, followed by a second centrifugation using the same conditions. The supernatant was discarded. The tube was drained for 5 minutes by inversion on a filter paper in order to remove the remaining supernatant. The pellet was dissolved in $150 \mu \mathrm{L}$ of a $2 \mathrm{M}$ lithium chloride (purchased from Lobachemie, CAS: 7447-41-8) solution. Then, $800 \mu \mathrm{L}$ of absolute ethanol was added and a pipette was used for mixing to carefully dissolve the GAGs. This solution was transferred to an Eppendorf tube and left for 5 minutes, and then the solution was centrifuged at 2,000 rpm for 10 minutes. The supernatant was aspirated and the resulting pellet was dried overnight.

\section{Thin layer chromatography GAG characterization} The TLC conditions described by Humbel [13] were modified as follows: dried GAG pellets were dissolved in $20 \mu \mathrm{L}$ phenol red solution $0.05 \%$ (purchased from Sigma-Aldrich, CAS: 143-74-8).

If the amount of precipitated GAGs was too elevated, the volume of 30 or $40 \mu \mathrm{L}$ phenol red solution was added; $8 \mu \mathrm{L}$ was applied on a TLC cellulose glass plates $(20 \times 20 \mathrm{~cm}$, purchased from Merck 1.05716.0001). Starting with the origin, every $2 \mathrm{~cm}$, six lines were drawn with a soft pencil. These indicated the borders for each solvent system; six TLC developing tanks were used. The samples were spotted on the TLC plate over a length of $1.5 \mathrm{~cm}$, at $0.5 \mathrm{~cm}$ from each sample and approximately $2 \mathrm{~cm}$ from the lower edge and at least 1.3 $\mathrm{cm}$ from the sides. Standards were prepared: $10 \mu \mathrm{L}$ of GAG standards, purchased from Sigma-Aldrich: Dermatane sulfate (DS, CAS: 54328-33-5), Heparane sulfate (HS, CAS: 57459-72-0), Chondroitin sulfate (C4S, CAS: 39455-18-0 and C6S, CAS: 9082-07-9), and Keratan sulfate (purchased from Glycofinechem, CAS: 9056-36-4) at $1 \mathrm{mg} / \mathrm{mL}$ in $0.05 \mathrm{M}$ Sodium hydroxide $(\mathrm{NaOH})$ and extracted GAGs were dissolved in $20 \mu \mathrm{L}$ of red phenol solution (precipitated GAGs obtained as described above). Solvents were prepared just before the chromatography following the instructions given in Table 1.

The plate was subsequently placed into six different tanks, which contained decreasing amounts of ethanol. One complete run required approximately 7 hours. The plate was allowed to dry overnight. Chromatograms were stained with $0.1 \%$ toluidine blue (purchased from Sigma-Aldrich, CAS: 92-31-9) in 70\% ethanol/acetic acid (95:5) and destained with $1 \%$ acetic acid solution (purchased from Sigma-Aldrich, CAS: 64-19-7). The plate was allowed to dry overnight.

\section{Enzyme activity assays}

Enzyme activity assays are the gold standard for diagnosis confirmation and determination of the MPS types and subtypes. The diagnosis is based on specific enzymatic assays performed in plasma, leukocytes or fibroblasts. Recently, DBS samples have been used for these assays [14]. This approach offers several advantages, including a simple and expedited sample collection, minimal invasiveness, reduced sample volume, easy sample handling, storage for extended periods of time 
and the possibility of using DBS samples for assaying the activity of any lysosomal enzyme. Fluorometric methods which had already been validated $[15,16]$, were completed for the evaluation of $\alpha$-iduronidase (MPS I) and arylsulfatase B (MPS VI). To evaluate iduronate-2-sulfatase (MPS II), we adapted the method of Voznyi et al. [17] as follows:

\section{Iduronidase assay in DBS samples (MPS I)}

Twenty microliters of sodium formate buffer $(50 \mathrm{mmol} /$ $\mathrm{L}, \mathrm{pH} 2.8$ ) containing $0.3 \mu \mathrm{g} / \mathrm{L}$ of D-saccharic acid-1,4lactone (purchased from Sigma-Aldrich, CAS: 61278$30-6$ ) and $20 \mu \mathrm{L}$ of water as elution liquid and $20 \mu \mathrm{L}$ of $2 \mathrm{mmol} / \mathrm{L}$ 4-methylumbelliferyl $\alpha$-L-idopyranosiduronic acid, sodium salt (purchased from Toronto Research Chemicals INC, CAS: 89157-94-8) in distilled water as the substrate, were added to microtiter plates, together with a $3 \mathrm{~mm}$-diameter punched circle from DBS (3.6 $\mu \mathrm{L}$ of blood). The microtiter plates were incubated for 20 hours at $37^{\circ} \mathrm{C}$ using an agitator (Heidolph Instruments $\mathrm{GmbH} \& \mathrm{Co}$. KG, Germany) at $600 \mathrm{rpm}$. The microtiter plates were allowed to stand for 30 minutes at room temperature, and $300 \mu \mathrm{L}$ of ethylenediaminetetraacetic acid $0.13 \mathrm{~mol} / \mathrm{L}, \mathrm{pH} 11.3$ (purchased from Sigma-Aldrich, CAS: 107-15-3) was added to stop the reaction. Blanks were treated as described above but the substrate solution and stop solution were added after incubation. Finally, each sample was transferred into a cuvette and completed with stop solution up to $2 \mathrm{~mL}$. Fluorescence (excitation: $365 \mathrm{~nm}$; emission: $450 \mathrm{~nm}$, cuvette volume: $1 \mathrm{~mL}$ ) of the enzyme product 4-methylumbelliferone (4-MU) (purchased from Sigma-Aldrich, CAS: 90-33-5) was measured with a Jasco FP-750 spectrofluorometer. The fluorescence readings were corrected for blanks, and the results were compared with the fluorescence from a calibrator. A calibration curve was prepared using different dilutions of 4-MU standards (0 - $500 \mu \mathrm{mol} / \mathrm{L}$ ). Enzymatic activity was expressed as micromoles of substrate hydrolyzed per liter of blood per hour $\left(\mu \mathrm{mol} / \mathrm{L}^{*} \mathrm{~h}\right)$.

\section{Iduronate sulfatase assay in DBS samples (MPS II)}

To $1.5 \mathrm{~mL}$ test tubes containing $3 \mathrm{~mm}$ diameter punched circle $(3.6 \mu \mathrm{L}$ of blood), we added $50 \mu \mathrm{L}$ of bovine serum albumin (BSA, purchased from Sigma-Aldrich, CAS: $9048-46-8) 0.2 \%$ as the elution liquid. After gentle mixing for 30 minutes at $37^{\circ} \mathrm{C}$, test tubes were centrifuged at 2,000 rpm for 10 minutes at room temperature. In microtiter plates, we introduced $10 \mu \mathrm{L}$ of supernatant and we added $20 \mu \mathrm{L}$ of $1.25 \mathrm{mmol} / \mathrm{L}$ 4-methylumbelliferyl $\alpha$-L-idopyranosiduronic acid 2-sulfate disodium salt (purchased from Toronto Research Chemicals INC, CAS: 1045020-74-3) previously dissolved in sodium acetate buffer (purchased from LOBA Chemie, CAS: $127-09-3)(0.1 \mathrm{~mol} / \mathrm{L}, \mathrm{pH} 5.0)$. The microtiter plates were incubated for 24 hours at $37^{\circ} \mathrm{C}$ using an agitator at $600 \mathrm{rpm}$. After the incubation, we added $40 \mu \mathrm{L}$ of phosphate citrate buffer (sodium phosphate dibasic anhydrous, purchased from Sigma-Aldrich, CAS: 7558-
79-4, and citric acid monohydrate, purchased from Ridel- de Haen, CAS: 5949-29-1) (0.2 mol/L, pH 4.5) and $10 \mu \mathrm{L}$ of purified $\alpha$-iduronidase from bovine testis (LEBT M2 purchased from Moscerdam substrates). The microtiter plates were incubated a second time for 24 hours at $37^{\circ} \mathrm{C}$ using an agitator at $600 \mathrm{rpm}$. The microtiter plates were allowed to stand for 30 minutes at room temperature, and $200 \mu \mathrm{L}$ of carbonate-bicarbonate buffer sodium (carbonate, purchased from Reacting, REF: 3565 , and sodium bicarbonate, purchased from SigmaAldrich, CAS: $144-55-8)(0.5 \mathrm{~mol} / \mathrm{L}, \mathrm{pH} 10.5)$ were added to stop the reaction. Blanks were treated as described above but the substrate solution and stop solution were added at the end of second incubation. Finally, each sample was transferred into a cuvette and completed with a stop solution up to $2 \mathrm{~mL}$. Fluorescence was read at excitation $360 \mathrm{~nm}$ and emission at $450 \mathrm{~nm}$ for the enzyme product 4-MU.

\section{Arylsulfatase B assay in DBS samples (MPS VI)}

A 2-mm diameter filter paper was punched $(2 \mu \mathrm{L}$ of blood) with a standard paper punch and $45 \mu \mathrm{L}$ of distilled water and $30 \mu \mathrm{L}$ of $15 \mathrm{mmol} / \mathrm{L}$ lead acetate in sodium acetate buffer $(50 \mathrm{mmol} / \mathrm{L}, \mathrm{pH} 5.0)$ were added as the elution liquid and $75 \mu \mathrm{L}$ of $10 \mathrm{mmol} / \mathrm{L}$ 4-methylumbelliferyl-sulfate (purchased from Sigma-Aldrich, CAS: $15220-11-8)$ in sodium acetate buffer $(0.05 \mathrm{M}, \mathrm{pH} 5.0)$ as the substrate. The microtiter plates were incubated for 6 hours at $37^{\circ} \mathrm{C}$ using an agitator at $600 \mathrm{rpm}$. The microtiter plates were allowed to stand for 30 minutes at room temperature and $150 \mu \mathrm{L}$ of glycine-sodium hydroxide buffer (glycine, purchased from Sigma-Aldrich, CAS: 56-40-6 and sodium hydroxide, purchased from Panreac, CE: 215-185-5) (85 mmol/L, pH 10.5) was added to stop the reaction. Blanks were treated as described above but the substrate solution and stop solution were added after incubation. Finally, each sample was transferred into a cuvette and completed with a stop solution up to $2 \mathrm{~mL}$. Fluorescence (excitation: $365 \mathrm{~nm}$; emission: $450 \mathrm{~nm}$, cuvette volume: $1 \mathrm{~mL}$ ) of the enzyme product 4-MU was measured with a Jasco FP-750 spectrofluorometer.

As recommended, when arylsulfatase B or iduronate sulfatase activity was found to be low, a second sulfatase (iduronate sulfatase or arylsulfatase B) was measured to rule out multiple sulfatase deficiencies.

The specific enzyme essays for patients with Sanfilippo syndrome and for those suspected of Morquio syndrome were performed in referenced laboratories abroad since enzyme assays for these types are not available in our laboratory.

\section{RESULTS}

Analysis of 88 urine samples yielded 26 positive GAG test results, 5 inconclusive results, and 57 negative results. All patients with a negative GAG test showed quantitative GAG values within the normal range. Of 
Table 1. Procedures for TLC separation of GAGs extracted from urine.

\begin{tabular}{|c|l|c|}
\hline Tanks & Solvents (proportions by volume and masse) & Elution time (min) \\
\hline I & Calcium Acetate: 0.5 N Acetic Acid: Ethanol (3.36 g: 60 mL: $90 \mathrm{~mL})$ & 30 \\
\hline II & Calcium Acetate: 0.5 N Acetic Acid: Ethanol (6.74 g: $75 \mathrm{~mL}: 75 \mathrm{~mL})$ & 55 \\
\hline III & Calcium Acetate: 0.5 N Acetic Acid: Ethanol (6.74 g: $90 \mathrm{~mL}: 60 \mathrm{~mL})$ & 65 \\
\hline IV & Calcium Acetate: 0.5 N Acetic Acid: Ethanol (6.74 g: $105 \mathrm{~mL}: 45 \mathrm{~mL})$ & 75 \\
\hline V & Calcium Acetate: 0.5 N Acetic Acid: Ethanol (6.74 g: $120 \mathrm{~mL}: 30 \mathrm{~mL})$ & 80 \\
\hline VI & Calcium Acetate: 0.5 N Acetic Acid: Ethanol (6.74 g: $135 \mathrm{~mL}: 15 \mathrm{~mL})$ & 80 \\
\hline
\end{tabular}

Calcium Acetate (purchased from Sigma-Aldrich, CAS: 5743-26-0).

those with inconclusive GAG tests, 1 of 5 showed quantitative GAG values slightly elevated, whereas all of those with positive GAG tests had an increased GAG concentration in urine.

TLC was carried out for all patients with total GAG levels strongly or slightly elevated, all those patients suspected of MPS IV, even with a low urinary excretion of GAG (3 cases), and those patients exhibiting symptoms consistent with mucopolysaccharidosis, including the microlipidosis and several glycoprotein storage disorders.

All patients with increased GAG concentrations had a pathological profile on TLC corresponding to different GAGs excreted and were referred to a specific enzyme diagnosis.

Measurement of enzyme activity in DBS was performed in those patients who had a specific pathologic chromatographic pattern $(n=26)$ and those who were suspected clinically to have MPS IV $(n=3)$ even with normal levels of total urinary GAGs and no specific pattern on TLC. A summary of quantitative GAG analysis in all patients confirmed to have an MPS and their subsequent enzyme confirmations are shown in Table 2. Twenty-six patients from nineteen families were diagnosed with MPS I, II, III, and VI. The percentage of consanguineous marriage among confirmed MPS cases was $80.76 \%$. All patients were diagnosed after the age of 3 years except for two patients (P18, P25), for whom the diagnosis was made at 9 months and 17 months following the confirmation of a sister's diagnosis.

The common disease-related symptoms in patients diagnosed with MPS I, II, and VI were short stature, multiple joint contractures, inguinal/umbilical hernias, hepatomegaly, mild to severe skeletal changes, coarse facial features, and developmental delay. The oldest patient with MPS III A (8.6 years) exhibited multiple symptoms including loss of speech; sleep disturbances, dementia, hyperactivity, impulsivity and obstinacy, and seizures that started at the age of 8 . Her sibling, (9 months) only exhibited symptoms of frequent upper respiratory infections. The patient with MPS IIIB (4.9 years), presented with speech delay, hyperactivity, aggressiveness, sleep disturbances, mild hepatomegaly, mild coarse facial features, and hypertrichosis. For patients clinically suspected of MPS IV, enzyme activity testing of N-acetylgalactosamine-6-sulfate sulfatase and $\beta$-galactosidase activities, essential in diagnosing MPS IVA and IVB, respectively, was performed to rule out this diagnosis, based initially on clinical symptoms.

In one case with GAG levels slightly elevated, TLC analysis showed strange spots not compatible with any of the MPS types (Figure 2, lane 5). As GAGs are present also in bones and cartilages, their levels can be elevated in other diseases affecting these tissues, such as mucolipidosis [18]. A diagnosis of mucolipidosis III was confirmed based on clinical and radiological findings, and elevated activity of lysosomal enzymes (measured on DBS sample) including $\alpha$-iduronidase and iduronate-2-sulfatase. Among patients with inconclusive GAG test, three patients with GAG levels within normal ranges presented clinical similarities with diagnosed mucolipidosis III patient: short stature, multiple joint contractures, mild coarse facial features, and developmental delay. We performed a TLC analysis and found the same abnormal patterns (Figure 2, Lane 6). In the last infant with inconclusive GAG test, somatic features and GAG levels within normal ranges, a strong band was seen on TLC analysis, the position of which could not be confused with other MPS or mucolipidosis disorders (Figure 2, Lane 7). She is under investigation at the time of writing.

\section{DISCUSSION}

There is a growing body of evidence that early initiation of disease-specific therapy in MPS I, II, and VI leads to a substantial modification of the natural course of the disease. To achieve these goals, we are the first Moroccan/North African laboratory to invest in the diagnosis of mucopolysaccharidosis by enzymatic essays using dried blood spots. We proceeded by a simple, inexpensive, and practical first line combined procedure. This approach was derived from a combination of pre-existing methods such as GAG tests, quantitative urinary 
Table 2. Clinical and biochemical characteristics of the Patients diagnosed with MPS.

\begin{tabular}{|c|c|c|c|c|c|c|c|c|c|c|}
\hline $\begin{array}{l}\text { Family/ } \\
\text { patient }\end{array}$ & $\begin{array}{c}\text { Diagnostic } \\
\text { age } \\
\text { (years) }\end{array}$ & $\begin{array}{l}\text { Gen- } \\
\text { der }\end{array}$ & $\begin{array}{c}\text { Consan- } \\
\text { guinity }\end{array}$ & $\begin{array}{l}\text { Pheno- } \\
\text { type }\end{array}$ & $\begin{array}{c}\text { Urinary } \\
\text { GAG } \\
\text { (mg/mmol } \\
\text { creatinine })^{b}\end{array}$ & $\begin{array}{c}\text { Urinary GAG } \\
\text { normal ranges } \\
\text { (mg/mmol } \\
\text { creatinine) }\end{array}$ & $\begin{array}{l}\text { Enzyme } \\
\text { deficiency }\end{array}$ & $\begin{array}{c}\text { Enzymatic } \\
\text { Activity }\end{array}$ & $\begin{array}{c}\text { Enzyme } \\
\text { activities } \\
\text { normal ranges } \\
\text { in DBS }\end{array}$ & $\begin{array}{c}\text { Diag- } \\
\text { nosis }\end{array}$ \\
\hline F1/P1 & 11.2 & $\mathbf{F}$ & + & HS & 90.90 & $3.3-13.7$ & $\begin{array}{c}\text { Alpha-L- } \\
\text { iduronidase }\end{array}$ & $0.1\left(\mu \mathrm{mol} / \mathrm{L}^{*} \mathrm{~h}\right)$ & $2.1-11.7$ & MPS-I \\
\hline F1/P2 & 12.3 & $\mathbf{M}$ & + & HS & 75.80 & $3.3-13.7$ & $\begin{array}{c}\text { Alpha-L- } \\
\text { iduronidase }\end{array}$ & $0.1\left(\mu \mathrm{mol} / \mathrm{L}^{*} \mathrm{~h}\right)$ & $2.1-11.7$ & MPS-I \\
\hline F2/P3 & 3.1 & $\mathbf{M}$ & + & IH & 117.83 & $9.5-25.7$ & $\begin{array}{c}\text { Alpha-L- } \\
\text { iduronidase }\end{array}$ & $0.0\left(\mu \mathrm{mol} / \mathbf{L}^{*} \mathbf{h}\right)$ & $2.1-11.7$ & MPS-I \\
\hline F2/P4 & 7.4 & $\mathbf{F}$ & + & IH & 117.12 & $6.7-15.5$ & $\begin{array}{c}\text { Alpha-L- } \\
\text { iduronidase }\end{array}$ & $0.0\left(\mu \mathrm{mol} / \mathrm{L}^{*} \mathrm{~h}\right)$ & $2.1-11.7$ & MPS-I \\
\hline F3/P5 & 15.5 & $\mathbf{F}$ & + & IH & 102.68 & $3.3-13.7$ & $\begin{array}{c}\text { Alpha-L- } \\
\text { iduronidase }\end{array}$ & $0.1\left(\mu \mathrm{mol} / \mathrm{L}^{*} \mathrm{~h}\right)$ & $2.1-11.7$ & MPS-I \\
\hline F4/P6 & 8.3 & $\mathbf{M}$ & + & HS & 75.80 & $6.7-15.5$ & $\begin{array}{c}\text { Alpha-L- } \\
\text { iduronidase }\end{array}$ & $0.1\left(\mu \mathrm{mol} / \mathrm{L}^{*} \mathrm{~h}\right)$ & $2.1-11.7$ & MPS-I \\
\hline F5/P6 & 5.8 & $\mathbf{F}$ & + & HS & 96.91 & $7.9-16.2$ & $\begin{array}{c}\text { Alpha-L- } \\
\text { iduronidase }\end{array}$ & $0.2\left(\mu \mathrm{mol} / \mathrm{L}^{*} \mathrm{~h}\right)$ & $2.1-11.7$ & MPS-I \\
\hline F6/ P6 & 7.1 & $\mathbf{F}$ & - & HS & 95.68 & $6.7-15.5$ & $\begin{array}{c}\text { Alpha-L- } \\
\text { iduronidase }\end{array}$ & $0.0\left(\mu \mathrm{mol} / \mathbf{L}^{*} \mathbf{h}\right)$ & $2.1-11.7$ & MPS-I \\
\hline F6/ P6 & 10.8 & $\mathbf{M}$ & - & HS & 95.05 & $3.3-13.7$ & $\begin{array}{c}\text { Alpha-L- } \\
\text { iduronidase }\end{array}$ & $0.0\left(\mu \mathrm{mol} / \mathbf{L}^{*} \mathbf{h}\right)$ & $2.1-11.7$ & MPS-I \\
\hline F7/ P10 & 8.7 & $\mathbf{F}$ & + & HS & 56.70 & $6.7-15.5$ & $\begin{array}{c}\text { Alpha-L- } \\
\text { iduronidase }\end{array}$ & $0.1\left(\mu \mathrm{mol} / \mathrm{L}^{*} \mathrm{~h}\right)$ & $2.1-11.7$ & MPS I \\
\hline F5/ P11 & 9.3 & $\mathbf{M}$ & + & HS & 88.94 & $6.7-15.5$ & $\begin{array}{c}\text { Alpha-L- } \\
\text { iduronidase }\end{array}$ & $0.1\left(\mu \mathrm{mol} / \mathrm{L}^{*} \mathrm{~h}\right)$ & $2.1-11.7$ & MPS-I \\
\hline F8/ P12 & 7.6 & $\mathbf{M}$ & - & HS & 75.88 & $6.7-15.5$ & $\begin{array}{c}\text { Alpha-L- } \\
\text { iduronidase }\end{array}$ & $0.1\left(\mu \mathrm{mol} / \mathrm{L}^{*} \mathrm{~h}\right)$ & $2.1-11.7$ & MPS-I \\
\hline F9/ P13 & 4.9 & $\mathbf{M}$ & + & HS & 68.33 & $7.9-16.2$ & $\begin{array}{c}\text { Alpha-L- } \\
\text { iduronidase }\end{array}$ & $0.1\left(\mu \mathrm{mol} / \mathrm{L}^{*} \mathrm{~h}\right)$ & $2.1-11.7$ & MPS-I \\
\hline F10/ P14 & 7.1 & $\mathbf{M}$ & + & HS & 60.51 & $6.7-15.5$ & $\begin{array}{c}\text { Alpha-L- } \\
\text { iduronidase }\end{array}$ & $0.1\left(\mu \mathrm{mol} / \mathrm{L}^{*} \mathrm{~h}\right)$ & $2.1-11.7$ & MPS-I \\
\hline F11/ P15 & 10.8 & $\mathbf{M}$ & - & HS & 59.15 & $3.3-13.7$ & $\begin{array}{c}\text { Alpha-L- } \\
\text { iduronidase }\end{array}$ & $0.1\left(\mu \mathrm{mol} / \mathrm{L}^{*} \mathrm{~h}\right)$ & $2.1-11.7$ & MPS-I \\
\hline F12/ P16 & 10.9 & $\mathbf{F}$ & - & HS & 71.89 & $3.3-13.7$ & $\begin{array}{c}\text { Alpha-L- } \\
\text { iduronidase }\end{array}$ & $0.1\left(\mu \mathrm{mol} / \mathrm{L}^{*} \mathrm{~h}\right)$ & $2.1-11.7$ & MPS-I \\
\hline F13/ P17 & 6.9 & $\mathbf{M}$ & + & & 162.05 & $6.7-15.5$ & $\begin{array}{c}\text { Iduronate-2- } \\
\text { sulfatase }\end{array}$ & $0.1\left(\mu \mathrm{mol} / \mathbf{L}^{*} \mathrm{~h}\right)$ & $9-29$ & MPS-II \\
\hline F14/ P18 & 0.9 & $\mathbf{F}$ & + & & 115.86 & $13.3-36.3$ & $\begin{array}{c}\text { Heparan-N- } \\
\text { sulfatase }\end{array}$ & $\begin{array}{c}0.2 \\
(\mathrm{nmol} / \mathrm{mg} / 17 \mathrm{~h})^{\mathrm{c}}\end{array}$ & - & \begin{tabular}{|c|} 
MPS- \\
IIIA \\
\end{tabular} \\
\hline F14/ P19 & 8.6 & $\mathbf{F}$ & + & & 69.05 & $6.7-15.5$ & \begin{tabular}{|c|}
$\begin{array}{c}\text { Heparan-N- } \\
\text { sulfatase }\end{array}$ \\
\end{tabular} & $\begin{array}{c}0.4 \\
(\mathrm{nmol} / \mathrm{mg} / 17 \mathrm{~h})^{\mathrm{c}} \\
\end{array}$ & - & \begin{tabular}{|c|} 
MPS- \\
IIIA
\end{tabular} \\
\hline F15/ P20 & 4.9 & M & + & & 79.95 & $7.9-16.2$ & $\begin{array}{c}\mathrm{N}- \\
\text { acetylglucosami }\end{array}$ & $\begin{array}{c}0.0 \\
(\mathrm{nmol} / \mathrm{mg} / \mathbf{1 7 h})^{\mathrm{c}}\end{array}$ & - & \begin{tabular}{|c|} 
MPS- \\
IIIB
\end{tabular} \\
\hline F16/ P21 & 15.5 & $\mathbf{F}$ & + & & 72.08 & $3.3-13.7$ & Arylsulfatase B & $1.82(\mu \mathrm{mol} / \mathrm{L} * \mathrm{~h})$ & $12-30$ & \begin{tabular}{|c|} 
MPS- \\
VI
\end{tabular} \\
\hline F17/ P22 & 9.3 & $\mathbf{M}$ & + & & 96.83 & $6.7-15.5$ & Arylsulfatase B & $0.46\left(\mu \mathrm{mol} / \mathrm{L}^{* h}\right)$ & $12-30$ & $\begin{array}{c}\text { MPS- } \\
\text { VI }\end{array}$ \\
\hline F18/ P23 & 14.8 & $\mathbf{F}$ & + & IH & 77.50 & $3.3-13.7$ & $\begin{array}{c}\text { Alpha-L- } \\
\text { iduronidase }\end{array}$ & $0.1\left(\mu \mathrm{mol} / \mathbf{L}^{*} \mathrm{~h}\right)$ & $2.1-11.7$ & MPS-I \\
\hline F18/ P24 & 5.7 & $\mathbf{F}$ & + & IH & 111.90 & $7.9-16.2$ & $\begin{array}{c}\text { Alpha-L- } \\
\text { iduronidase }\end{array}$ & $0.1\left(\mu \mathrm{mol} / \mathrm{L}^{*} \mathrm{~h}\right)$ & $2.1-11.7$ & MPS-I \\
\hline F18/ P25 & 1.5 & $\mathbf{M}$ & + & IH & 155.80 & $8.1-35$. & $\begin{array}{c}\text { Alpha-L- } \\
\text { iduronidase }\end{array}$ & $0.1\left(\mu \mathrm{mol} / \mathrm{L}^{*} \mathrm{~h}\right)$ & $2.1-11.7$ & MPS-I \\
\hline F19/ P26 & 8.4 & $\mathbf{M}$ & + & & 78.00 & $6.7-15.5$ & $\begin{array}{c}\text { Iduronate-2- } \\
\text { sulfatase }\end{array}$ & $0.1\left(\mu \mathrm{mol} / \mathrm{L}^{*} \mathrm{~h}\right)$ & $9-29$ & MPS-II \\
\hline
\end{tabular}

a - in MPSI disorder, ${ }^{b}$ - reference values are age-dependent, ${ }^{c}$ - performed at outside laboratory, enzymatic essays were performed in leucocytes, normal ranges are 10 - 45 nmol/mL/h, uGAGs - urinary Glycosaminoglycan, MPS - Mucopolysaccharidosis, + - Present, - - Absent, M - Male, F - Female. 


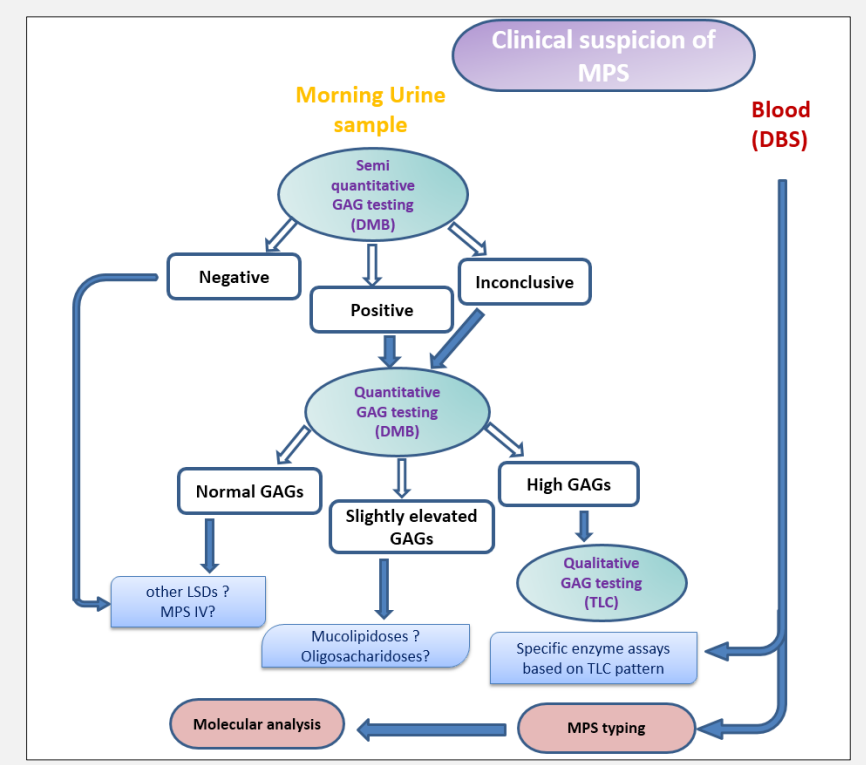

Figure 1. Flow-chart for our laboratory diagnosis of MPS.

DBS - Dried blood Spot, DMB - Dimethyl methylene blue, GAGs - Glycosaminoglycans, LSDs - Lysosomal storage diseases, TLC - Thin layer chromatography.

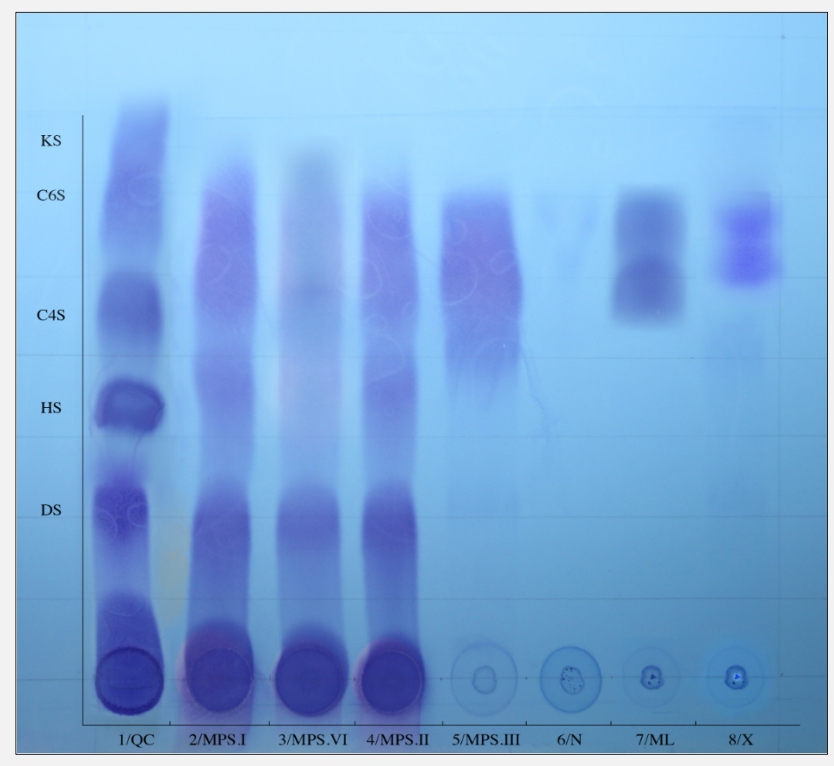

Figure 2. Thin layer chromatography of standards GAGs and GAGs isolated from MPS diagnosed patients and healthy control.

Urinary GAGs were isolated and chromatographed as described. Lane 1: QC, quality control (DS - dermatan sulfate, HS - heparan sulfate, C4S - chondroitin 4 sulfate, C6S - chondroitin 6 sulfate, and KS - keratan sulfate. Lane 2: patient with Hurler syndrome (MPSI). Lane 3: patient with Maroteaux-Lamy syndrome (MPS VI). Lane 4: patient with Hunter syndrome (MPSII). Lane 5: patient with Sanfilippo syndrome (MPS IIIB). Lane 6: healthy control. Lane 7: patient with micolipidosis III. Lane 8: patient on diagnosis with somatic features. 
GAG evaluation, and TLC characterization modified and simplified to lead us to a specific enzyme activity assay using DBS samples. The use of GAG tests was useful for a quick screening of MPS among those patients suspected of suffering from MPS (IH/HS, II, III, or VI). The test enabled us to make a quick detection, confirmation, or exclusion of an MPS diagnosis, thus reducing the number of individuals requiring future testing. This proved to be very helpful especially in rural areas of the country where consanguineous marriage is frequent.

We used simultaneous quantitative and qualitative methods to reduce the chances of a false-negative result. The quantitative data were also used to normalize GAGs on TLC plates by adjusting for individual variation in excretion. This ensured uniform chromatographic behavior and facilitated estimation of the relative abundance of specific GAGs. The TLC analysis method allows the identification of an abnormal GAG pattern in all MPS and mucolipidosis patients and can help in the diagnosis of several other oligosaccharidoses based on abnormal patterns detected. It was not possible to distinguish MPS I from MPS II, on the basis of urinary GAG. Measuring both the iduronidase and iduronate-2-sulfatase enzyme activities was therefore required to make a proper diagnosis. Since MPS I is the more common type in the North African populations [19,20], the iduronidase was assayed first. Maroteaux-Lamy syndrome (MPS VI) patients had a TLC pattern easily distinguished from MPS I and II with excretion of a large excess of DS and presence or absence of trace amounts of HS. In MPS III patients, a straightforward banding pattern was observed corresponding to HS, and two bands were observed in mucolipidosis III. Furthermore, it should also be emphasized that the TLC pattern provided a diagnostic orientation of the different types of MPS and/or mucolipidosis III/II, which directed us to focus on patients having symptoms consistent with mucopolysaccharidosis diseases and exhibiting characteristics of oligosaccharidosis abnormal patterns on TLC analysis.

Definitive diagnosis of inherited lysosomal storage diseases is based on specific enzymatic assays performed on plasma, leukocytes, fibroblasts, and lately, dried blood spot samples. We confirmed the diagnosis of patients affected by several mucopolysaccharidosis types using DBS samples for appropriate enzyme assays.

This method offers several advantages, including a simple and expedited sample collection, minimal invasiveness, reduced sample volume and easy sample handling and storage for extended periods. DBS samples can be used for assaying the activity of other lysosomal enzymes to reach a diagnosis.

Clinical signs of different mucopolysaccharidosis types are variable from one disorder to another, but also in terms of the severity between patients suffering from the same MPS disorder. The total GAG levels in urine seem to be proportional to the severity of the symptoms. Indeed, among MPS I patients, three patients (P4, P12, and P14) who shared facial dysmorphism, joint stiffness, hepatomegaly, umbilical hernia symptoms, and ear, nose, and throat (ENT) infections, presented different clinical symptoms that could be related to the levels of GAG. Patient P4 (GAG 117.12) had severe central and peripheral nervous system involvement, cardiac symptomatology, and hearing loss. Patient P12 (GAG 75,88 ) had mild cardiac symptomatology, and patient P14 (GAG 60, 51) showed less severe symptoms.

We performed enzyme activity assays on 3 patients clinically suspected with MPS IV, even though uGAG levels were normal, in order to avoid false-negatives. These three patients exhibited normal cognitive function and presented with chest deformity, short stature, and growth retardation. Both N-acetylgalactosamine-6-sulfatase and B-galactosidase were within normal ranges, and the diagnosis was excluded. These findings taught us to rely on the clinical presentation that should generate clinical suspicion of MPS IV like joint hypermobility (of the wrist in particular) as it is unique to MPS IV, kyphosis/gibbus, genu valgum, and shortness of breath [21].

In this study, we have used a targeted screening program for children suspected of having MPS in our university hospital. Our pilot study results allow us to submit proposals to implement the first national newborn screening (NBS) for MPS I. The key factors in recommending MPS I for inclusion in NBS are the strongly improved efficacy of early-onset therapy with HSCT/ ERT, or ERT, making early diagnosis beneficial for the patient and society.

Several limitations, however, should be acknowledged. First, the patients diagnosed in this study do not represent the distribution of MPS in the Moroccan population. Second, DMB-based spectrophotometry can give rise to false negatives, especially in MPS III and IV [4]. In addition, in some cases; high levels of GAG may be due to other pathologies, such as diabetes, lupus, arthritis, or mucolipidosis [18]. Finally, the method requires an investment of time (at least 4 days of handling are required to obtain a final confirmation) and an experienced manipulator.

\section{CONCLUSION}

An early and accurate diagnosis of MPS is critical not only in permitting disease-specific genetic counseling but also in guiding appropriate national supportive care and disease-specific therapy. This study is the first work diagnosing MPS in Morocco based on enzymatic activity assays in DBS specimens. This method, which is efficient in diagnosing MPS subtypes, will offer several advantages to our laboratory in achieving its goal of becoming a reference center for the diagnosis of MPS in North Africa. 


\section{Acknowledgment:}

We thank the Manchester metabolic team, Prof. Simon A. Jones. Dr. Karen Tylee, and Dr. Heather Church, for assistance with performing enzyme essays for MPS III patients.

We thank Prof. Robert Wynn for his valuable help in implementing the diagnosis and the treatment of MPS. We thank all patients and their families who participated in this study.

\section{Funding Sources:}

This research did not receive any specific grant from funding agencies in the public, commercial, or not-forprofit sectors.

\section{Declaration of Interest:}

The authors have no competing interests.

\section{References:}

1. Muenzer J. The mucopolysaccharidosis: a heterogeneous group of disorders with variable pediatric presentations. J Pediatr 2004; 144:S27-34 (PMID: 15126981).

2. Clarke LA. The mucopolysaccharidosis: a success of molecular medicine. Expert Rev Mol Med 2008;10;e1:1-18 (PMID: 254912 47)

3. Dembure PP, Drumheller JE, Barr SM, Elsas LJ. Selective Urinary Screening for Mucopolysaccharidoses. Clin Biochem 1990; 23(1):91-6 (PMID: 2110043).

4. Mahalingham K, Janani S, Priya S, Elango EM, Sundari RM. Diagnosis of Mucoplysaccharidoses. How to avoid False Positives and False Negatives. Indian J Pediatr 2004;71:29-32 (PMID: 149 79382)

5. Neufeld EF, Muenzer J. The mucopolysaccharidosis. In: Scriver CR, Beaudet AL, Sly WS and Valle D (eds) The Metabolic and Molecular Bases of Inherited Disease. McGraw-Hill Co, New York, pp 3421-52.

https://ommbid.mhmedical.com/content.aspx?sectionid=2255441 $61 \&$ bookid $=2709$

6. Hopwood JJ, Morris CP. The mucopolysaccharidoses: diagnosis, molecular genetics and treatment. Mol Biol Med Mol 1990;7(5): 381-404 (PMID: 2128891).

7. Andrade F, Prieto JA, Elorz J, Martin S, Sanjurjo P, AldamizEchevarria L. Stability of urinary glycosaminoglycans in patients with mucopolysaccharidoses. Clin Chim Acta 2008;388:73-7 (PMID: 17964291).

8. Lage S, Prieto JA, Andrade F, Sojo A, Sanjurjo P, AldámizEchevarría LJ. Reliability of a visual test for the rapid detection of mucopolysaccharidoses: GAG test $\left({ }^{\circledR}\right)$. J Clin Lab Anal 2011; 25:179-84 (PMID: 21567465)

9. Lopez-Marin L, Gutuerrez-Solana V, Azuara EL, las Heras RS, Rodriguez AD, Extremera VC. Detection by Urinary GAG Testing of Mucopolysaccharidosis Type II in an At-Risk Spanish Population. JIMD Rep 2013;10:61-8 (PMID: 23430804).
10. Gray G, Claridge P, Jenkinson L, Green A. Quantitation of urinary glycosaminoglycans using dimethylene blue as a screening technique for the diagnosis of mucopolysaccharidoses: an evaluation. Ann Clin Biochem 2007;44:360-3 (PMID: 17594782).

11. Wijburg FA, Wegrzyn G, Burton BK, Tylki-Szymańska A. Mucopolysaccharidosis type III (Sanfilippo syndrome) and misdiagnosis of idiopathic developmental delay, attention deficit/hyperactivity disorder or autism spectrum disorder. Acta Paediatr 2013; 102(5):462-70 (PMID: 23336697).

12. Humbel R, Marchal C, Fall M. Differential diagnosis of mucopolysaccharidosis by means of thin-layer chromatography of urinary acidic glycosaminoglycans. Helv Paediatr Acta. 1969;24(6): 648-50 (PMID: 4244361).

13. Humbel R, Chamoles NA. Sequential thin layer chromatography of urinary acidic glycosaminoglycans. Clin Chim Acta.1972 40(1):290-3 (PMID: 4262516).

14. Civallero G, Michelin K, De Mari J, et al. Twelve different enzyme assays on dried-blood filter paper samples for detection of patients with selected inherited lysosomal storage diseases. Clin Chim Acta. 2006;372:98-102 (PMID: 16712827).

15. Chamoles NA, Blanco MB, Gaggioli D, Casentini C. Hurler-Like phenotype: enzymatic diagnosis in dried blood spots on filter paper. Clin Chem 2001;47:2098-102 (PMID: 11719472).

16. Hein LK, Meikle PJ, Dean CJ, et al. Development of an assay for the detection of mucopolysaccharidosis type VI patients using dried blood-spots. Clin Chim Acta 2005;353:67-74 (PMID: 1569 8592).

17. Voznyi YV, Keulemans JL, VanDiggelen OP. A fluorimetric enzyme assay for the diagnosis of MPS II (Hunter disease). J Inherit Metab Dis 2001;24:675-80 (PMID: 11768586).

18. Tomatsu S, Okamura K, Maeda H, et al. Keratan sulphate levels in mucopolysaccharidoses and mucolipidoses. J Inherit Metab Dis 2005;28:187-202 (PMID: 15877208).

19. Alif N, Hess K, Straczek J, et al. Mucopolysaccharidosis type I: Characterization of a common mutation that causes Hurler syndrome in Moroccan subjects, Ann Hum Genet 1999;63:9-16 (PMID: 10738517).

20. Tebani A, Zanoutene-Cheriet L, Adjtoutah Z, et al. Clinical and Molecular Characterization of Patients with Mucopolysaccharidosis Type I in an Algerian Series. Int J Mol Sci 2016;17:743 (PMID: 27196898).

21. Hendriksz CJ, Harmatz P, Beck M, et al. Review of clinical presentation and diagnosis of mucopolysaccharidosis IVA. Mol Genet Metab 2013;110:54-64 (PMID: 23665161). 